Editorial

\title{
Psych-An Open Access Journal
}

\section{Bryan Pesta}

Department of Management, Cleveland State University, 2121 Euclid Ave. BU 327, Cleveland, OH 44115, USA;

b.pesta@csuohio.edu

Received: 19 June 2019; Accepted: 19 June 2019; Published: 20 June 2019

\section{Introduction}

It is my great pleasure, on behalf of the editorial board and myself, to introduce Psych, MDPI's new multidisciplinary, open-access journal for the social and behavioral sciences. We hope this journal will make a novel contribution to the publishing ecology. The journal is intended to provide a forum for integrated social and behavioral science research.

\section{Aims \& Scope}

The aims of this journal are reflected by my own experience. I received my doctorate in experimental psychology, but I am a professor in a business college (at Cleveland State University). I primarily conduct differential psychology research, though often not at the individual level. Similar to my own background, I intend for the journal to be interdisciplinary, with a primary focus on human behavior and psychology. No topic is off limits, if backed by empirical rigor.

One of the central goals of Psych will be to integrate research from across disciplines. Thus, we welcome articles from psychology, as well as allied social and behavioral sciences. This includes research at the intra-individual, individual, and macro-social level. Further, it includes research from outside of the traditional social sciences. During the last 20 years, there has been an explosion of neuroscientific and genetics research, which has spawned a number of exciting new venues for questions previously encompassed by the traditional social sciences. While formal consilience has not yet been reached, part of the aim of this journal is to integrate findings and methodologies from these fields into the social sciences. As such, the journal welcomes sociogenomics, cultural neuroscience, and other research which relates to classic social scientific questions. In this regard, we would like to help bridge the gap between the hard and soft sciences.

Moreover, there have been significant advances in psychometrics over the last two decades, including the proliferation of free open-source software for conducting research (e.g., network psychometrics and advanced item response theory modeling). This journal seeks to incorporate such novel methodological approaches into applied social science research. As such, we are interested in research that applies new developments in, for instance, structural equation modeling and confirmatory factor analysis to practical research questions.

Finally, given the ongoing replication crisis in psychology and elsewhere, we also welcome replication studies, especially those with large samples that seek to replicate highly-cited works with small samples. While some editors deem replications to be less worthy of publication, we believe that they are integral to the scientific process. In line with our emphasis on replication, this journal also encourages qualitative and quantitative reviews.

In short, we envision this journal as a place for integrated social, psychological, and genetic research using modern methods and standards of science. 


\section{Editorial and Publication Processes and Peer Review}

As editor-in-chief, I plan to delegate most of the decisions to the editorial board. This board is well qualified, with over 30 members, with specialties including biomedical science, clinical psychiatry, psychometrics, child development, meta-cognition, gender roles, animal behavior, and public health. Manuscripts will be distributed to the relevant editors, who will preview them for relevance and quality. Those which pass initial screening will be sent to two or more reviewers for evaluation of the importance of the manuscript, the quality of the methods, and the adequacy of results and conclusions, as well as English language proficiency. English-language editing services are available for those that need it.

\section{Special Issues}

As with other MDPI journals, Psych intends to run special issues on key topics. Whereas research is often unfocused due to the variety of interests across thousands of authors, the purpose of these special issues is to provide focus on a particular research question or topic with a view to focusing our collective efforts. Special issues are usually, but not always, hosted by a member of the editorial board.

\section{Publishing Considerations}

Given that Psych is an online-only journal, there is no set limit on the length of the papers, giving authors the opportunity to document their methods and findings in as much detail as possible, either in the manuscript or the supplementary material. The methodology should be explained in sufficient detail to allow full replication. MDPI offers timely reviewing and a quick turn-around for accepted papers. This way, researchers can focus on getting science done instead of wasting time waiting for months on end for reviews to come in or for papers to be finalized. We believe that increasing the effectiveness of scientific publishing is key to human technological and cultural progress.

\section{Conclusion}

These are exciting times both for Psych and for the social sciences in general. In moving forward, we hope to help spearhead the effort to bridge the gap between traditional hard and soft sciences, and in doing so highlight novel methods and findings which were out of reach to researchers in generations past.

(C) 2019 by the author. Licensee MDPI, Basel, Switzerland. This article is an open access article distributed under the terms and conditions of the Creative Commons Attribution (CC BY) license (http://creativecommons.org/licenses/by/4.0/). 